\title{
OPTIMIZATION OF DOSING TANK EMPTYING USING SPIRAL VIBRATION
}

\author{
David Zurovec', Jan Necas', Jan Divis', Jakub Hlosta', Jiri Zegzulka', Katerina Urbanova² \\ 1 VSB-Technical University of Ostrava, ENET Centre, 17. listopadu 15/2172, 70833 Ostrava-Poruba, Czech \\ Republic, e-mail: david.zurovec@vsb.cz \\ 2 DSD-Dostal, a.s., Bystricka 38, 75114 Drevohostice, Czech Republic
}

Received: 2018.06.29

Accepted: 2018.08.01

Published: 2018.09.01

\begin{abstract}
This article addresses the optimization of a dosing tank using a spiral harmonic motion. The dosing tank is used for ashort-term storage of cohesive sand, which is then released into a tubular mold. Originally, a solution based on the principle of wiping the material using rotary blades and brushes was used to fill the molds. However, this method was not effective enough. This solution suffered from uneven dosing as well as a loss of material. The mold filling time ranged around 20 seconds. During the course of optimization of the dosing tank, a new design of the tank was created and external energy in aform of harmonic spiral vibrations was introduced into the system. The chosen shape of the harmonic spiral motion proved to be the most suitable for continuous emptying of the cohesive sand from the dosing tank into the tubular mold in a very short time. There was also a significant elimination of material losses. It was determined that the frequency of harmonic motion affects uniform dispensing of material fromtanks.
\end{abstract}

Keywords: spiral vibration, dosing tank, cohesive sand.

\section{INTRODUCTION}

Industrial enterprises are forced to invest in the development of technology due to technological advances in all disciplines of mechanical engineering and ever-increasing demands for speedy manufacturing processes. When designing transport and storage facilities, it is appropriate to use studies and knowledge from various areas of transport and handling equipment designed not only for bulk materials $[1,2,3]$. The present study addresses the optimization of emptying a dosing device designed for the short-term storage of an exact amount of cohesive sand. In general, storage facilities such as tanks or silos are used to hold loose material in a closed space for the necessary amount of time. The construction of the storage facilities is dimensioned according to the required storage time as well as the mechanical and physical properties of the stored bulk mate- rials. Mechanical and physical properties significantly influence the behavior of bulk materials in storage processes $[4,5,6]$. In fact, negative behaviour such as vaulting are not uncommon during emptying tanks. The optimal emptying of tanks requires knowledge of the operating conditions and detailed information about the stored material. This above all includes the aforementioned mechanical and physical properties of the stored material, the shape and size of the tank, the hopper and the discharge opening. In terms of the nature of the tank emptying, we distinguish two ways of material flow: mass and core flow. Mass flow is manifested by the gradual draining of material from the tank in order, in which it was introduced to the tank. To achieve this, an optimal construction design of the storage device is required depending on the properties of the stored material [7]. However, in reality this is often not achieved, and it requires the use of external sources of en- 

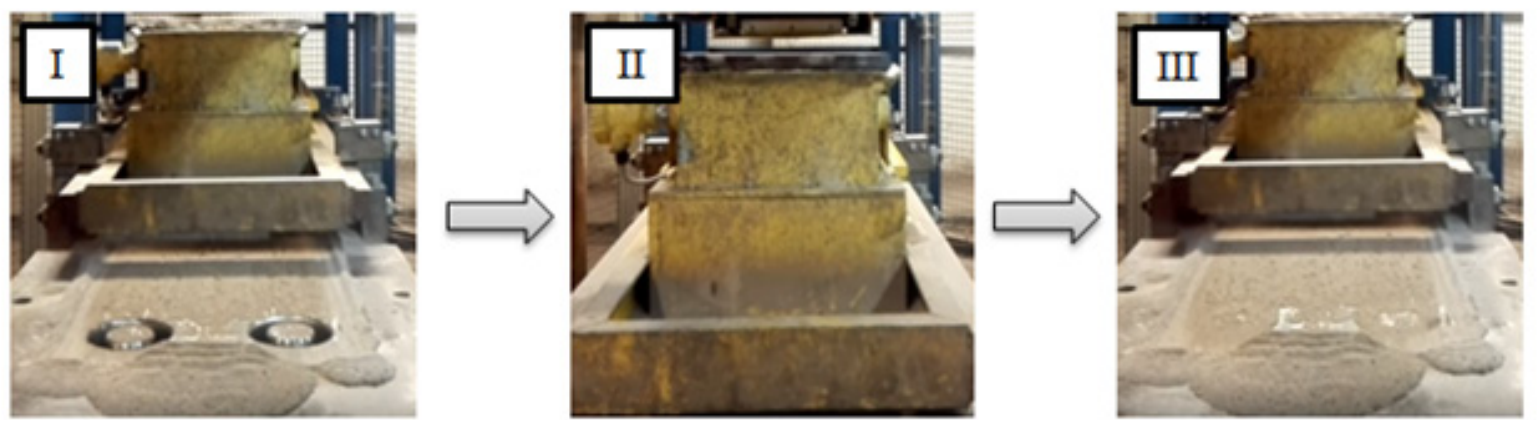

Fig. 1. The principle of dosing cohesive sand into tubular molds [15]

ergy, such as vibrations, acoustic waves or air $[8,9,10]$. The core flow is characterized by the principle that the material loaded inthe tank first, discharges last. Here, the material above the discharge opening is discharged first and the material adjacent to the walls of the tank remains still, creating so-called "dead zones". The material located in such "dead zones" often adheres to the walls of the tank due to longer static persistence, which is perceived as a failure state $[11,12]$. Other failure states including static vaults, cavities or tunnels may also occur in storage devices, which all negatively affect continuous emptying. However, the advancement of technology provides methods such as the Discrete Element Method (DEM), to detect and monitor failure states in transport and storage facilities. The advantage of using the DEM simulation method lies in software verification of planned changes in design of a device being developed or optimized $[13,14]$.

\section{DESCRIPTION OF THE CURRENT TECHNOLOGICAL PROCESS}

During the course of this research, an analysis of the current technology of sand dosing into tubular molds was performed. The technology was developed many years ago and it no longer meets today's requirements. The existing technology is based on the principle of wiping sand with a total dose weight of $4 \mathrm{~kg}$ into a tubular mold using rotary blades and brushes located in a cubical dosing tank. Fig. 1 summarizes the dosing method into three steps: I, II, III. In the first step (I), the dosing tank arrives above the pair of openings of the tubular mold and the discharge outlet is opened. In the second step (II), the process of material wiping using a system of rotary blades and brushes is initialized. This process takes place for almost 15 seconds. In the third step (III), the dosing tank re- turns to the filling area to start a new filling cycle. During the filling of the dosing tank, the tubular mold is prepared for the next filling cycle.

However, this method was not effective enough as it often resulted in uneven dosing and material loss, as shown in Fig. 1 in steps (I) and (III). Furthermore, the mold filling time was no longer sufficient to meet current requirements and it was necessary to proceed to a comprehensive optimization of the process. The aim of the optimization was to ensure a uniform filling of the tubular mold to eliminate material losses as well as decrease the filling time by two-thirds. In the first step of the optimization, the current state was evaluated while the mechanical and physical characteristics of the sand were measured. Based on the data collected about the process and the bulk material used, the optimization direction was determined. During the course of optimization of the dosing tank, a new design of the tank was created and external energy in aform of harmonic spiral vibrations was introduced into the system.

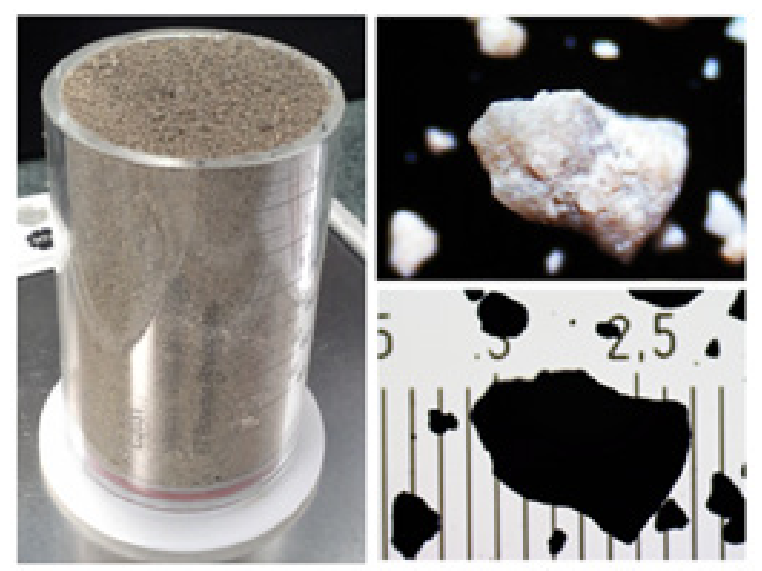

Fig. 2. A sample of sand used during the experiment 


\section{MECHANICAL AND PHYSICAL PROPERTIES OF SAND}

In order to optimize the process of emptying the dosing device, a sample of the bulk material was analyzed. The bulk material used here wasthe sand used for the production of fittings in the foundry industry, which is shown in Fig. 2.

\section{Angle of internal friction $\varphi_{\mathrm{e}}$}

The angle of internal friction $\varphi_{\mathrm{e}}$ characterizes flow properties of bulk materials. This includes movements, resistances and bonds between individual particles. The angle of internal friction determines the shear properties of the mass, which define the flowability of the sample being examined. The angle of internal friction was measured using aring shear tester Schulze RST-01. Fig. 3 shows the results ofmeasuring the angle of internal friction of the sand $\left(\varphi_{\mathrm{e}}=43^{\circ}\right)$. The dependence of normal stress $\sigma$ on shear stress $\tau$ is shown as well. Based on the measured values of the angle of internal friction of the sand, it was necessary to provide more energy to overcome the inter-particle bonds and resistances.

\section{Wall friction angle $\phi_{w}$}

The measurement of the wall friction angle was performed on the Jenike direct shear tester. The measurement principle consists of measuring the time dependence of the shear stress $\tau$, which is required to shift bulk material over the contact

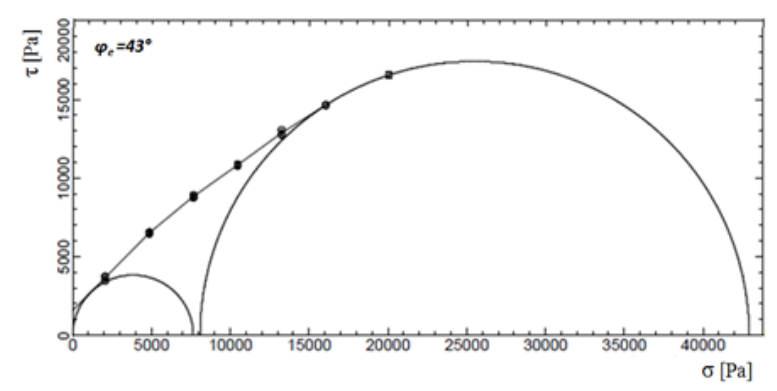

Fig. 3. Results of internal friction and flowability measurement using the RST-01 tester

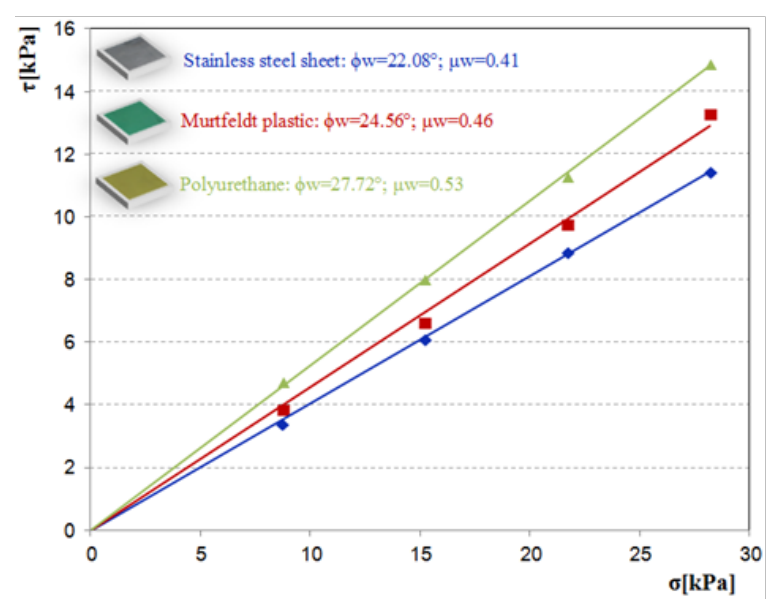

Fig. 4. Results of wall friction angle measurements

material, while gradually increasing normal stress $\sigma$. The following contact materials were used: A) stainless steel sheet; B) Murtfeldtstandard "S" plastic; C) polyurethane. The results of measured values of wall friction angle $\phi_{\mathrm{w}}$ and the wall friction coefficient $\mu_{\mathrm{w}}$ are summarized in a single graph, which is shown in Fig. 4. From a comparison of the results of external friction measured on individual contact materials, it is seen that the stainless-steel sheet exhibited the lowest resistance to movement.

\section{Angle of repose $\Psi_{s}$}

The angle of repose was measured using a measuring stand consisting of a steel bowl on which the material was gradually fed through a vibratory feeder. The bowl was placed on a rotary stand that allowed the pile to be monitored from $0^{\circ}$ to $360^{\circ}$. The numerical angle of repose values are shown in Table 1, while Fig. 5 shows graphical results of the angle of repose measurements. The average angle of repose was $\Psi_{\mathrm{s}}=52.1^{\circ}$. This implies that sand is very cohesive when filled and emptied during storage processes.

\section{Particle size distribution}

A CILAS 1190 laser particle size analyzer was used for granulometric analysis of the

Table 1. The numerical angle of repose values

\begin{tabular}{|c|c|c|c|c|c|c|c|c|}
\hline & \multicolumn{9}{|c|}{ Position } \\
\cline { 2 - 9 } & 1 & 2 & 3 & 4 & 5 & 6 & 7 & 8 \\
\hline Angle of repose & 52.6 & 53.4 & 52.4 & 52.09 & 52.3 & 50.2 & 51.1 & 51.8 \\
\hline Angle of repose-Avg. & \multicolumn{10}{|c|}{52.1} \\
\hline
\end{tabular}



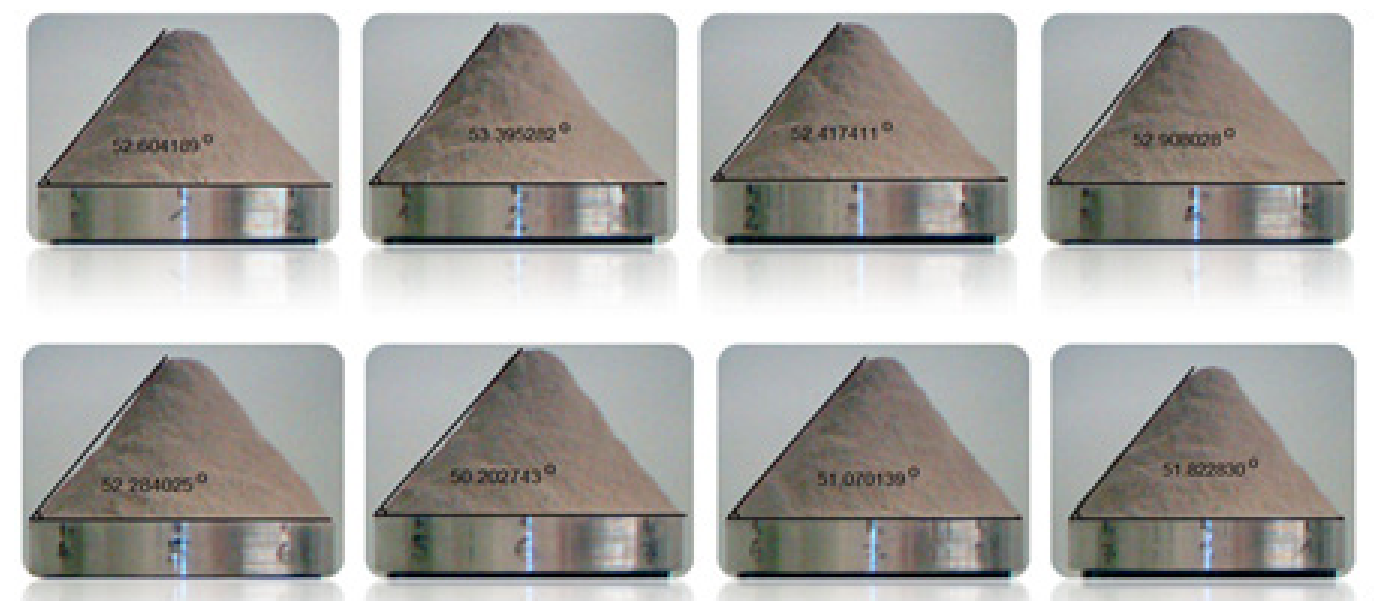

Fig. 5. Results of angle of repose measurements

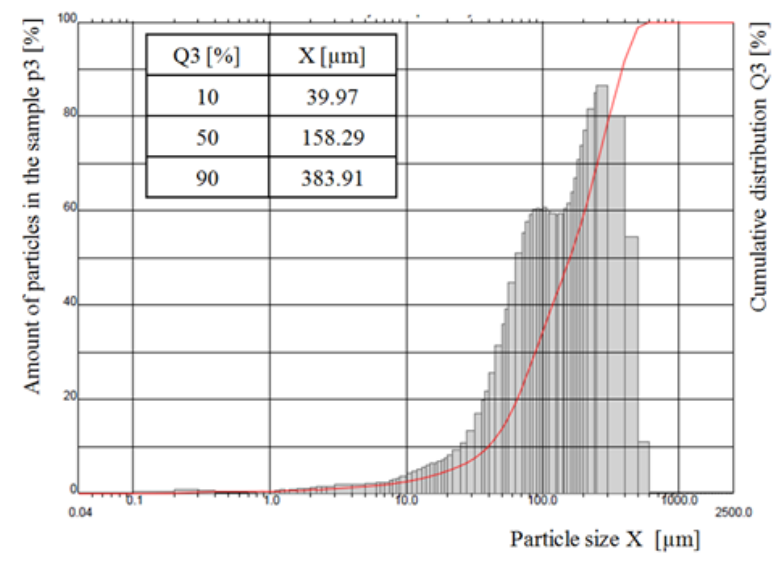

Fig. 6. Results of particle size distribution measurements

sample. Coherent light from low-power laser diodes, emitted at $830 \mathrm{~nm}$ wavelength, passes through a cuvette containing a sample of the analyzed material dispersed in the corresponding liquid and the light beam isscattered. The particle size distribution of sand ranges from $1 \mu \mathrm{m}$ to $600 \mu \mathrm{m}$, see Figure 6. Most particles in the sample ranged from $100 \mu \mathrm{m}$ to $400 \mu \mathrm{m}$.

\section{OPTIMIZATION OF DOSING TANK}

Based on the measured mechanical and physical properties, sand was added into a group of cohesive materials and an external power source was required for uniform emptying of the dosing device. Micro-vibrations with spiral path oscillation were selected as an external power source. The shape of the spiral vibration was achieved by using a pair of NO12 vibration
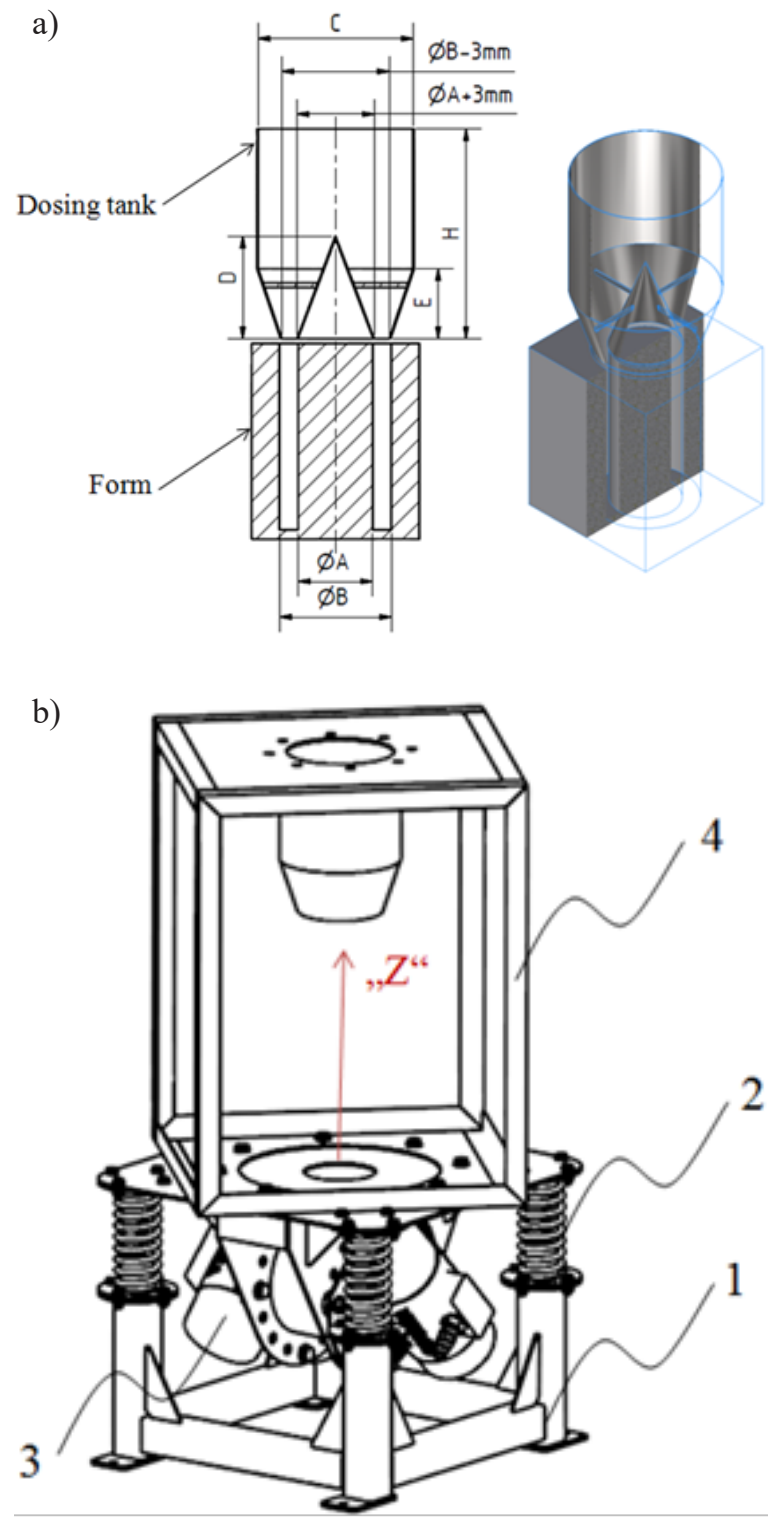

Fig. 7. a) new design of the dosing device, b) experimental stand 


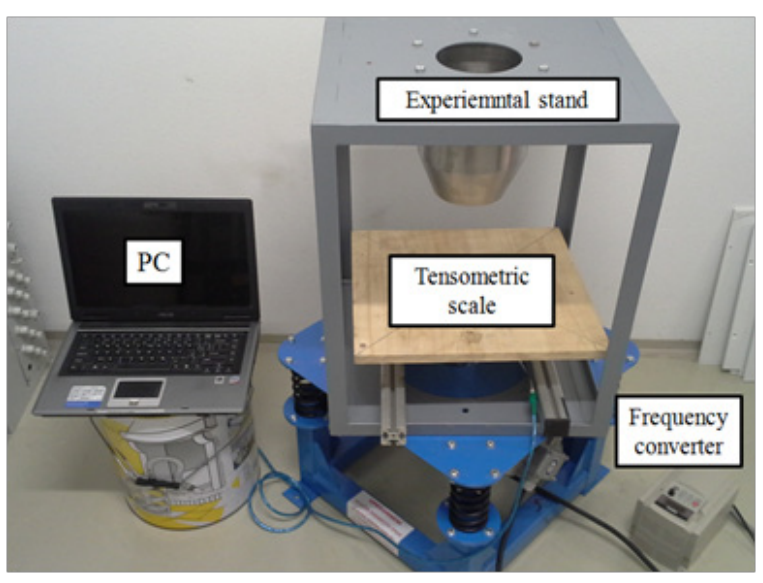

Fig. 8. Assembly of the measuring apparatus

motors installed on the vibrating part and rotated by $90^{\circ}$ with respect to each other, see Fig. $7 b)$. Vibration motors positioned this way provide a combination of two harmonic motions: partial rotation around the " $Z$ " axis and partial feed in the "Z" axis. The combination of these two motions creates spiral micro-oscillation. In this way, the stability and symmetry of the overall assembly during gravitational emptying of the dosing tank are ensured. From the measurement of the external friction angle, a stainless-steel sheet was chosen for the production of the dosing tank. Based on a comprehensive assessment of the measured mechanical and physical properties of the used sand, a new shape and size of the tank was designed, and the minimum dimensions of the discharge outlet were determined, depending on the particle size distribution of the sand. Figure 7 shows: a) new design of a dosing device, b) experimental measuring stand. The experimental measuring stand consists of the following basic parts: 1-Fixed frame; 2-Flexible Elements 4x; 3-Vibrating part including the dosing tank; 4-Vibrator motors $\mathrm{NO} 12$.

\section{EXPERIMENT AND RESULTS}

In order to experimentally verify the functionality of the optimized dosing tank, a measuring apparatus was assembled consisting of the following: a PC, experimental stand, tensometric scale and frequency converter. The assembly of the measuring apparatus is shown in Figure 8. During the experimental measurements, the ef-
Table 2. Settings of the driving force $\mathrm{F}_{\mathrm{B}}$ depending on the oscillation frequency $f$ produced by pair of the N012 $0.15 \mathrm{~kW}$ vibration motors

\begin{tabular}{|c|c|c|c|c|}
\hline $\begin{array}{c}\text { Frequency } \\
\mathbf{f}[\mathrm{Hz}]\end{array}$ & 15 & 20 & 25 & 30 \\
\hline $\begin{array}{c}\text { Speed } \\
\mathbf{n}[\mathbf{r p m}]\end{array}$ & 852 & 1136 & 1420 & 1704 \\
\hline $\begin{array}{c}\text { Driving force } \\
\mathbf{F}_{\mathrm{B}}[\mathbf{N}]\end{array}$ & 325 & 579 & 904 & 1302 \\
\hline
\end{tabular}

fect of vibrations on the efficiency of emptying the dosing tank was assessed. Table 2 shows settings of the driving force $\mathrm{F}_{\mathrm{B}}$ depending on the oscillation frequency $f$ produced by pair of the $\mathrm{N} 012$ $0.15 \mathrm{~kW}$ vibration motors. The total stiffness emanating from the four elastic elements was $\mathrm{k}_{\mathrm{p}}=$ $123 \mathrm{~N} . \mathrm{mm}^{-1}$. A $4 \mathrm{~kg}$ sand sample was loaded into the dosing tank.

Figure 9 shows the emptying process of the dosing tank in various operating modes. In the first experiment, the sand behavior unaffected by vibrations was monitored. It turned out that the material is so cohesive that the tank could not be emptied by employing only a gravitational method. In the second experiment, vibrations of $15 \mathrm{~Hz}$ frequency corresponding to a driving force of $325 \mathrm{~N}$ were used. Even in this case, the sand could not be emptied from the tank and the entire volume remained in the tank. After increasing the frequency to $20 \mathrm{~Hz}$, the sand started to freely flow immediately after opening the discharge outlet. The emptying process was smooth with only slight deviations. Subsequently, the vibration frequency was set to $25 \mathrm{~Hz}$, which corresponds to the driving force of $904 \mathrm{~N}$. In this case, the emptying was very smooth and stable without signs of impact effects. At $30 \mathrm{~Hz}$, there were signs of greater dynamic effects during the emptying process, which are undesirable for the following processes. The emptying time for the tested frequencies was around $2.5 \mathrm{~s}$.

Based on the results from the experimental tests, the final design of the dosing tank was created, and suitable pneumatic vibration drives were selected which were positioned $90^{\circ}$ relative to each other. The driving force of a pair of pneumatic vibration drives was set to allow the optimal emptying of the dosing tank. Fig. 10 shows the final version of the dosing tank design used in real operation. 


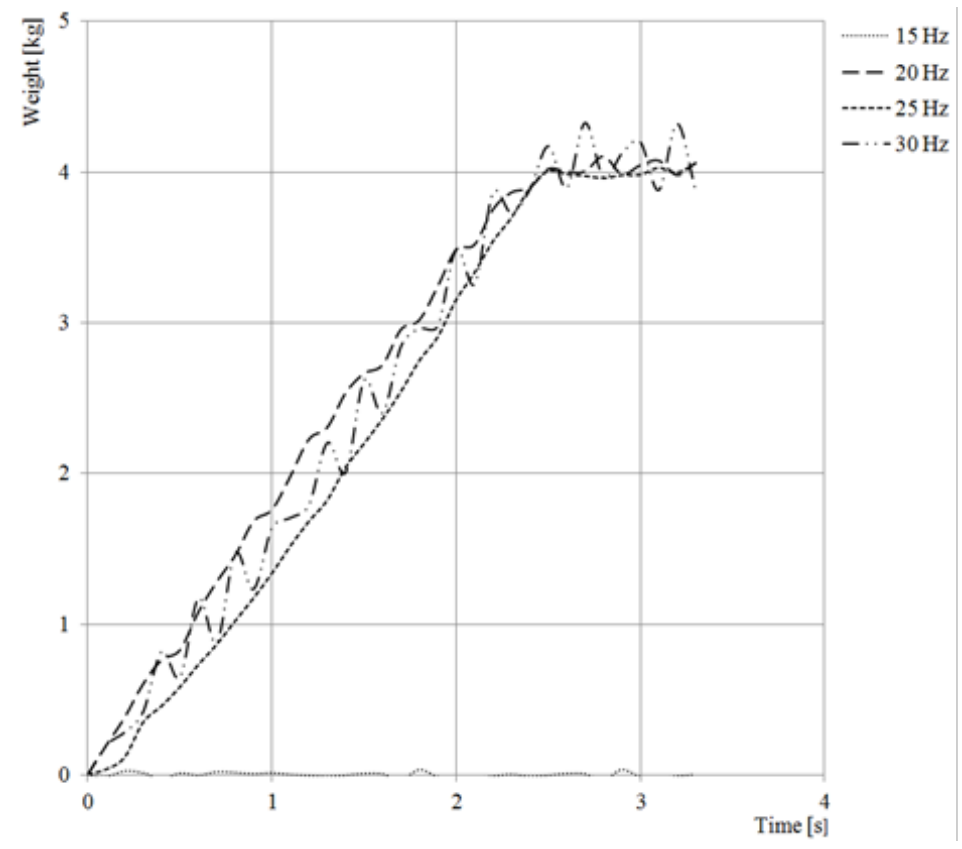

Fig. 9. The course of dosing tank emptying process

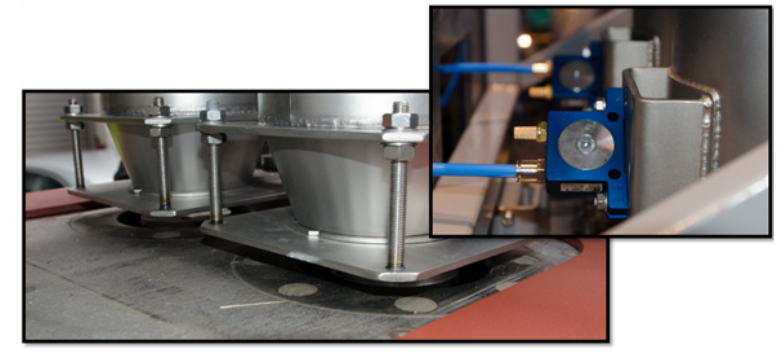

Fig. 10. Dosing tank design

\section{CONCLUSIONS}

The aim of this research was to optimize the method of emptying a dosing device designed for weighing and short-term storage of sand. Firstly, an analysis of the current process technology was performed. In the following step, the mechanical and physical properties of the used sand were measured, namely: angle of friction, wall friction, angle of repose and particle size distribution. Based on the measured values, the sand was assessed as very cohesive with a particle size ranging from $1 \mu \mathrm{m}$ to $600 \mu \mathrm{m}$. It was found, that the most suitable contact material for the production of the inner space of the dosing tank was stainless steel, which showed the lowest resistance to sand movement. On the basis of the collected data, a new shape and size of the dosing tank was designed, and the minimum size of the outlet was determined, depending on the particle size distribution of the sand. Due to the high cohesion of the sand, it was necessary to introduce external energy to the system. The most suitable vibrations for the process were selected. The shape of the vibration, in the form of harmonic spiral motion, proved to be the most suitable for the uniform and symmetrical discharge of sand from the tank. The experimental tests showed that the optimal driving force of a pair of vibration drives was $900 \mathrm{~N}$, depending on the weight of the vibrating parts and the stiffness of the flexible elements. The emptying time of the required volume of sand ranged around 2.5 seconds. Optimization of the emptying method met all requirements and was applied to real-life operation.

\section{Acknowledgements}

This paper was conducted within the framework of the project LO1404: Sustainable development of ENET Centre,project SP2018/47: Calibration and experimental devices for the research and validation of simulation models AND project SP2018/132: Research and development of innovative transport equipment for verification DEM method in process of bulk solid transportation. 


\section{REFERENCES}

1. Klepka T., Debski H., Rydarowski H. Characteristics of high-density polyethylene and its properties simulation with use of finite element method, Polimery, 54(9), 2009, 668-672.

2. Fedorko G, Molnar V., Dovica M., et al The use of industrial metrotomography in the field of maintenance and reliability of rubber-textile conveyor belts in closed continuous transport systemsm, Eksploatacja i niezawodnosc-maintenance and reliability, 18(4), 2016, 539-543.

3. Jachowicz T., Sikora R.Methods of forecasting of the changes of polymeric products properties, Polimery, 51(3), 2006, 177-185.

4. McGlinchey D. Bulk Solids Handling: Equipment Selection and Operation. Book: Blackwell Publishing Ltd., 2008, pp: 304.

5. Schulze D. Powders and bulk solids: behavior, characterization, storage and flow. Book: New York: Springer, 2008, pp: 511.

6. Ekmann J. M. and Le P. H. Coal Storage and Transportation. Reference Module in Earth Systems and Environmental Sciences, from Encyclopedia of Energy, 2004, 551-58.

7. Schulze D. Flow Properties of Powders and Bulk Solids [online]. [cit. 2014-04-10]. Accessible from: http://www.dietmar-schulze.de/grdle1.pdf.
8. Zhang Ch., Qiu C., Pu Ch., Fan X. and Cao P. The mechanism of vibrations-aided gravitational flow with everhanging style in hopper, Powder Technology, 327, 2018, 291-302.

9. Nedderman R.M., Tūzūn U. and Thorpe R.B. The effect of interstitial air pressure gradients on the discharge from bins, Powder Technology, 35(1), 1983, 69-81.

10. Ferrari G. and Bell T.A. Effect of aeration on the discharge behaviour of powders, Powder Handing Process, 10(3), 1998, 269-274.

11. Bertuola D., Volpato S., Canu P., Santomaso A. C. Prediction of Segregation in Funnel and Mass Flow Discharge, Chemical Engineering Science, 150, 2016, 16-25.

12. Tian T., Su J., Zhan J., Geng S., Xu G. and Liu X. Discrete and continuum modeling of granular flow in silo discharge, Particuology, 36, 2018, 127-138.

13. Cleary P.W. Large scale industrial DEM modelling. Engineering Computations, 21(2/3/4), 2004, 169-204.

14. Höhner D., Wirtz S., Scherer V. A study on the influence of particle shape on the mechanical interactions of granular media in a hopper using the Discrete Element Method, Powder Technology, 278, 2015, 286-305.

15. SEEIF Ceramic, a.s. [online]. SEEIF Ceramic, 2018 [cit. 2018]. Accessible from: http://ceramic.cz/. 